\title{
Electrochemical Screening Spot Test Method for Detection of Nickel and Cobalt lon Release From Metal Surfaces
}

Jellesen, Morten S.; Olsen, Christian Bang; Ruff, Samine; Spiewak, Radoslaw; Hamann, Dathan;

Hamann, Carsten R.; White, lan R.; Johansen, Jeanne D.; Thyssen, Jacob Pontoppidan

\section{Published in:}

Dermatitis

Link to article, DOI:

10.1097/DER.0000000000000389

Publication date:

2018

Document Version

Peer reviewed version

Link back to DTU Orbit

Citation (APA):

Jellesen, M. S., Olsen, C. B., Ruff, S., Spiewak, R., Hamann, D., Hamann, C. R., White, I. R., Johansen, J. D., \& Thyssen, J. P. (2018). Electrochemical Screening Spot Test Method for Detection of Nickel and Cobalt lon

Release From Metal Surfaces. Dermatitis, 29(4), 187-192. https://doi.org/10.1097/DER.0000000000000389

\section{General rights}

Copyright and moral rights for the publications made accessible in the public portal are retained by the authors and/or other copyright owners and it is a condition of accessing publications that users recognise and abide by the legal requirements associated with these rights.

- Users may download and print one copy of any publication from the public portal for the purpose of private study or research.

- You may not further distribute the material or use it for any profit-making activity or commercial gain

- You may freely distribute the URL identifying the publication in the public portal 


\section{Electrochemical screening spot test method for detection of nickel and cobalt ion release from metal surfaces}

\section{Original article}

Morten S. Jellesen ${ }^{1}$, Christian Bang Olsen ${ }^{1}$, Samine Ruff ${ }^{2}$, Radoslaw Spiewak ${ }^{3}$, Dathan Hamann ${ }^{4}$, Carsten R. Hamann $^{2}$, Ian R. White ${ }^{5}$, Jeanne D. Johansen ${ }^{2}$, Jacob P. Thyssen ${ }^{2}$

1) Technical University of Denmark, Department of Mechanical Engineering, Kgs. Lyngby, Denmark.

2) National Allergy Research Centre. Department of Dermatology and Allergy, Herlev-Gentofte Hospital, University of Copenhagen, Hellerup, Denmark.

3) Department of Experimental Dermatology and Cosmetology, Jagiellonian University Medical College, Krakow, Poland.

4. Division of Dermatology, Department of Internal Medicine, The Ohio State University, Columbus, OH, 43221, USA,

5) St. John's Institute of Dermatology, Guy’s Hospital, London SE1 9RT

Total word count: 3212

Number of tables/figures: 9

Number of References: 8

Key Words: allergy, cobalt, dermatitis, nickel, spot test.

Running Head:

Acknowledgement: Jacob Thyssen is a Lundbeck Foundation Fellow and is supported by an unrestricted grant.

Conflict of interests:

Morten S. Jellesen and Jacob Thyssen developed a cobalt spot test and sold it to SmarthHealth, Arizona, USA and receive annular royalties based on net sales.

Prior presentations: The content has not been published previously.

\section{Correspondence:}

Jacob Pontoppidan Thyssen, MD PhD

National Allergy Research Centre

Department of Dermatology and Allergy,

Herlev-Gentofte Hospital

University of Copenhagen

Kildegaardsvej 28, DK-2900 Hellerup, Denmark

Email: jacob.p.thyssen@regionh.dk

Phone: +45 39773150 Fax:+45 39777118 


\begin{abstract}
Background: Present screening methods to rapidly detect release of nickel and cobalt ions from metallic surfaces involve colorimetric dimethylglyoxime (DMG) and disodium-1-nitroso-2-naphthol-3,6-disulfonate based spot tests with a cotton bud. There is a risk of false negative test reactions as test outcomes are dependent on the pressure, area and duration of surface wiping.
\end{abstract}

Objectives: To develop a miniaturized electrochemical device that uses a voltage to accelerate nickel and cobalt release from the tested item and perform an initial validation.

Methods and results: A device was built in plastic and its performance was investigated using $0.5 \mathrm{ml}$ test solutions of, respectively, DMG and disodium-1-nitroso-2-naphthol-3,6-disulfonate. Cotton buds that had been wetted in test solution were pressed against different metal surfaces at various voltages $(0-9 \mathrm{~V})$ and a range of test durations $(0-120 \mathrm{sec})$. Duplicate testing for nickel and cobalt release was also done on a sample of 163 jewellery items.

Conclusions: This novel electrochemical device makes it possible to perform nickel and cobalt ion release testing without rubbing thereby reducing inter-individual differences in testing technique. The nickel testing with the device appeared to be superior to conventional DMG spot testing. 


\section{INTRODUCTION}

Metal allergy is prevalent worldwide, predominately due to prolonged and excessive skin contact with metallic items and leather products that release allergenic metal ions. In particular nickel, cobalt and chromium are common culprit allergens as they result in significant morbidity in both children and adults. $(1,2)$ For this reason, colorimetric spot tests have been developed to rapidly screen for metal ion release that exceeds the threshold levels for elicitation of allergic contact dermatitis. (3-5) These spot tests allow patients to avoid skin contact with metal ion releasing items that will result in allergic contact dermatitis, and clinicians can perform rapid and inexpensive exposure analyses of metallic items brought in by their patients.

The nickel spot test, which is based on dimethylglyoxime (DMG), is used both by dermatologists and by consumers, and is considered a reliable test method. (4) The test is positive when a white cotton bud applicator becomes pink after it has been rubbed against a metal surface that releases nickel in concentrations $>0.5$ microgram nickel $/ \mathrm{cm}^{2}$ per week. While the specificity of the DMG spot test is high (98\%), the sensitivity is only moderate (59\%). (4) Nickel allergic individuals can, therefore, rely on positive test results, as the metal surface under investigation indeed releases nickel ions in amounts that may elicit allergic nickel dermatitis following prolonged skin contact. However, negative test results do not necessarily ensure absence of excessive nickel release and may, therefore, result in accidental allergic nickel dermatitis, or even primary sensitization.

The recent introduction of a cobalt spot test gave dermatologists and scientists a novel tool to screen for cobalt ion release from metal surfaces. $(3,6)$ However, based on our experience, it is sometimes difficult to reliably detect positive test reactions in a real-life setting as the colour change from yellow to orange can be difficult to determine, or be masked by dirt, rust or other particulate matter on the item of interest. One example was a baker with cobalt allergy who was recently treated in our clinic due to allergic contact dermatitis in the interdigital space. (7) Metallic trays were suspected of releasing cobalt, but conventional cobalt spot testing with cottons sticks could not confirm cobalt release. However, a napkin soaked in cobalt spot test solution was then pressured against a tray for minutes and confirmed cobalt release. 
Based on our experience, nickel and cobalt spot testing may suffer from inter-individual testing differences and the cotton bud-based tests are not always sensitive enough. There was, therefore, a need to develop a new device for spot testing for nickel and cobalt with improved the sensitivity and decreased risk of interindividual subjective differences (Figure 1). To this end, we developed an electrochemical device based on anodic dissolution of nickel and cobalt found in the surface of examined products. In this article, we describe this electrochemical colorimetric spot test performance along with test results from X-ray fluorescence (XRF) analysis.

\section{MATERIALS AND METHODS}

\section{Theoretical considerations}

A constant voltage can be applied between the tested part connected as anode and an inert metallic part as cathode through a cotton swab wetted with colorimetric test solution. Faradays law, equation 1, gives a quantitative relationship between the flow of electricity and the amount of metal dissolution.

$$
m=\frac{I \cdot M \cdot t}{n \cdot F}
$$

In Faraday's law, equation 1, $\mathrm{m}$ is the mass of metal dissolution over time (t), and $\mathrm{I}$ is the anodic current, $\mathrm{n}$ the number of electrons, and F, Faraday's constant 96485 (C/mol). The anodic current will accelerate metal release and should in theory result in faster and more sensitive detection of nickel and cobalt as compared to standard colorimetric identification methods.

\section{Metals}

The following materials were used for nickel release studies: Aluminium, stainless steel AISI 316, and a guitar string (nickel-plated steel 250R, Fender, USA). In addition, nickel-plated stainless steel, electroplated nickel, electroless nickel plating (deposited by chemical means only), and electroplated samples were investigated (all samples used for teaching purposes at the Technical University of Denmark, Lyngby, Denmark). For cobalt release investigations, different custom-made cobalt-containing metal discs of the 
same batch as used by Julander et al. (6) were used. The authors had shown that these discs released cobalt in artificial sweat and also elicited positive cobalt patch test reactions in cobalt-allergic patients. $(3,8)$ The alloys are used as raw material in the manufacturing of wear parts for hard metal tools (Sandvik AB, Sandviken, Sweden) and as dental alloys (Dentaurum, Ispringen, Germany).

\section{Electrochemical device}

All experiments were carried out with a device as shown in Figure 1. In total, two prototypes were built from polymer materials (SPT Villecon A/S, Hillerød) and used throughout the validation study. The cathodic part of the electrical contact was a flexible metal strip (Cu Ni18 Zn20) designed to grip into the cotton swab inserted in the ampoule cylinder. The electrical contact for the anode was established via a flexible contact (a 2-part spring probe made of phosphor bronze supplied by RS-online ${ }^{\circledR}$, Denmark). The flexibility ensured that electrical contact was established once the cotton swab was pressed against the metal to be analysed. With this setup, the effects of voltage and analysis time were investigated with a constant load between device and test piece of $700 \mathrm{~g}$. The damage on tested metal surfaces was investigated using a light optical microscope ZEISS Axio Lab A1 (Zeiss, Germany). Polymer ampoules (James Alexander Corporation, USA) containing $0.5 \mathrm{ml} 0.9$ wt.\% NaCl, 3.8 wt.\% DMG in a 25/75 vol.\% mixture of water/ethanol in an internal glass cylinder were used for the nickel experiments, and ampoules (James Alexander Corporation, USA) containing $0.1 \mathrm{wt} . \%$ oxalic acid, $0.02 \mathrm{wt} . \%$ nitroso-R salt and $5.0 \mathrm{wt} . \%$ sodium acetate (disodium-1-nitroso2-naphthol-3,6-disulfonate) in deionized water were used for the cobalt experiments. All chemicals used were supplied by Sigma-Aldrich Chemie GmbH, Germany. The ampules were mounted on the drawer part of the device and pushed into the housing (depicted in Figure 2). Once the ampoule internal glass wall was pressed until breakage, the test solutions wetted the cotton swab to be pressed against the metal item of interest.

The applied voltage was supplied by 2 serial connected $1.5 \mathrm{~V}$ LR44 batteries (Renata ${ }^{\circledR}$ batteries) inside the drawer compartment, or by a power supply (EA-PS 2032-025) or a potentiostat (ACM Instrument Gill AC) when performing leakage current investigations. 


\section{Colorimetric test solutions}

For the conventional nickel spot test experiments, a cotton stick was wetted with 2 drops of $1 \mathrm{wt} . \%$ DMG dissolved in ethanol and 2 drops of 5M ammonia solution (Sigma-Aldrich Chemie Gmbh, Germany). For the conventional cobalt spot testing, 4 drops of a solution containing $0.1 \mathrm{wt} . \%$ oxalic acid, $0.02 \mathrm{wt} . \%$ nitroso-R salt and $5.0 \mathrm{wt} . \%$ sodium acetate (disodium-1-nitroso-2-naphthol-3,6-disulfonate) in deionized water were used. The wetted cotton sticks were then rubbed against the jewellery item for 20 seconds.

\section{Jewellery for validation}

For further validation of the device performance, 163 pieces of jewellery were analysed with the electrochemical device and compared with the outcome of conventional cobalt and nickel spot tests. All jewellery items had been XRF analysed prior to this study. (9) All tested samples contained nickel from 0.6 wt.\% to 75.7 wt.\% and were bought in United Kingdom, Poland and Japan. For the nickel validation, 163 jewellery pieces with nickel were tested and for the cobalt validation, 26 pieces were tested. All tests were conducted for 20 seconds with $0.5 \mathrm{ml}$ of the respective spot test solutions. All tests using the conventional cotton stick method were conducted for 20 seconds as described above.

\section{RESULTS}

\section{Nickel}

Investigation of time and constant voltage settings for electrochemical device

The effect of voltage and testing time on the release of nickel was investigated. As the voltage was increased above $3 \mathrm{~V}$, no additional effect on colour formation was observed (Figure 3).

The effect of testing time was investigated by increasing the duration of testing from $0-120$ seconds in steps of 10 seconds at a constant voltage of $3 \mathrm{~V}$ (Figure 4). After each experiment, the colour of the swab surface was photographed and light optical microscopy was performed on the metal surface in contact with the swab. There was a clear coloration of the cotton swab with a testing time $>10$ seconds. Light optical microscopy 
showed signs of degradation of the tested metal surface when testing time exceeded 45 seconds. After 60 seconds of testing, the corrosion degradation was naked eye visible.

Figure 5 shows the resulting current at a constant voltage level of $3 \mathrm{~V}$ for various metal samples over 120 seconds. The current measured was within 1 -3 mA for all samples. The current levels are proportional to the total ion release and/or oxidation processes taking place. It is important to mention that for stainless steel the total current contribution is arising from oxidation of $\mathrm{Ni}$ as well as $\mathrm{Cr}$ and $\mathrm{Fe}$. Clear red coloration from DMG nickel complex formation was seen on all samples except for the reference sample (pure aluminium). On the stainless steel (AISI 316) and nickel plated guitar string, a brownish discoloration was seen, presumably due to the high content of iron.

\section{Cobalt}

\section{Cobalt detection with electrochemical device}

The coloration of cotton swab after cobalt testing various cobalt containing items with the electrochemical device (120 seconds and a voltage of 3V) is given in Figure 6.

All tested items, except $\mathrm{G}$ and $\mathrm{H}$, resulted in an evident red coloration. The sample $\mathrm{H}$ was a control sample consisting of pure aluminium and showed no reddish coloration. The sample G had $15 \mathrm{wt} . \%$ cobalt content in the base alloy, but also a coating consisting of layers of $\mathrm{TiCN}, \mathrm{Al}_{2} \mathrm{O}_{3}$ and $\mathrm{TiN}$, which prevented the base alloy from releasing cobalt, while $\mathrm{H}$ was the negative control $(0 \mathrm{wt} . \% \mathrm{Co})$.

\section{Validation of device by jewellery testing}

In total, 163 and 26 pieces of jewellery were selected based on previous XRF analysis and in this study examined with the conventional nickel and cobalt spot test, respectively, as well as the electrochemical device. The same surface was analysed at different areas for conventional spot test and the electrochemical device. Of 163 nickel containing jewellery items, 113 (69.3\%) came out positive when testing was performed with the electrochemical device, whereas $88(54.0 \%)$ of 163 came out positive when using the conventional DMG test. A similar difference was detected in jewellery from all three countries. Four 
jewellery pieces were positive when using the DMG test, but negative when using the electrochemical device, whereas 25 pieces that were negative when using the DMG test were positive when using the electrochemical device. In particular, in items with low nickel concentrations according to the XRF analysis, the miniaturized electrochemical device test showed more positive test outcomes than conventional DMG spot testing (Figure 7). A similar validation was done for the cobalt spot test assays. For cobalt, 14 (53.8\%) of 26 pieces were positive when using the conventional cobalt spot test, whereas only 9 (34.6\%) of 26 were positive when testing was performed with the electrochemical device. Conventional cobalt spot testing identified 6 pieces with positive test reactions where testing with the electrochemical testing gave negative test results. However, only 1 piece was negative when tested with conventional cobalt spot test, but came out positive with the electrochemical device (Figure 8).

\section{DISCUSSION}

\section{Main findings}

We have developed and validated an electrochemical device, which allowed anodic dissolution of the metal under investigation, and showed that it represented a more reliable and sensitive test method for detection of nickel release compared to the traditional DMG test method. While the test also accelerated cobalt release and led to positive test results, testing of a sample of jewellery that contained cobalt showed that the electrochemical test was inferior to the traditional cobalt spot test. While the test per se is destructive, metal degradation after testing for 20 seconds at $3 \mathrm{~V}$ could only be seen by microscopic analysis and was not visible to the naked eye. Moreover, the device minimizes possibly hazardous skin contact with the colorimetric chemicals and is odourless when testing for nickel release since ammonia is not used. Typically ammonia is added to DMG to ensure alkaline $\mathrm{pH}$ for improved color change, however when using the electrochemical device we found that ammonia is not needed for a distinct color change to happen. By using the electrochemical device it is possible to test without the vigorous rubbing needed for conventional spot tests, potentially making test results less prone to inter- and intra-individual testing differences.

\section{Interpretations}


The described electrochemical device represents a well-examined starting point for future improvement and validation. The higher proportion of positive test reactions when using the electrochemical device compared to the conventional DMG test is explained by the increased dissolution of nickel ions present on the surface due to the voltage and current applied as described in Faradays law. Moreover, the electrochemical device showed enhanced cobalt release from dental alloys as compared with conventional cobalt spot testing. This could be explained by dissolution of a passivating chromium oxide layer caused by the electrochemical potential that in turn will allow cobalt release from the bulk $\mathrm{CoCr}$ alloy. This shows how the electrochemical device is able to detect ion release from a bulk metal alloy through porosities in a coating, which can be relevant for skin contact when handling corroded metal samples. Surprisingly, the device was inferior to the conventional cobalt spot test when a random sample of cobalt containing jewellery was examined. The conductivity of the cobalt spot test solution is higher than the DMG test solution used for nickel spot testing with the electrochemical device. However, the colour difference from negative to positive was not as apparent for the cobalt test when compared to the nickel test. We suspect that the less evident colour difference is the main reason for the reduced sensitivity of the electrochemical cobalt spot test. This was especially seen when testing earrings, where we tested millimetre-sized piercing posts. The electrochemical device only showed a thin colour line, corresponding to the thin posts, which was difficult to appreciate with the naked eye (Figure 9). Many cobalt-containing jewellery pieces were negative to both the electrochemical and the conventional cobalt spot tests, which can be explained by the fact that some alloys contain the element without releasing the metal ion from the surface under investigation.

\section{Limitations}

The electrochemical device had certain limitations. To accelerate metal release by the use of an applied anodic current, the item of interest need to be electrically conducting and hence be metallic. This means that the test method is useless on non-metallic items, e.g. leather. Moreover, the colorimetric solution used has to give an evident positive colour reaction, which may be difficult if a small surface area like a piercing post is examined. Although the increased sensitivity of nickel detection associated with the electrochemical device is expected to be clinically relevant, there is a theoretical risk that we enhance nickel release beyond clinical 
relevance. However, avoidance of nickel release is important in nickel-allergic individuals and the low sensitivity of the conventional DMG test justifies this. Future validation against the EN 1811 reference test for compliance of the European nickel regulation would be meaningful. We observed jewellery pieces that were only positive with one of the two tests, respectively, hereby indicating that none of the tests were able to completely detect ion release.

\section{CONCLUSION}

This novel electrochemical device makes it possible to perform metal ion release tests without rubbing thereby limiting inter-individual differences in testing technique. In nickel testing, the device appeared to be more sensitive than conventional DMG spot testing. 


\section{FIGURES}

Figure 1. A photo of the electrochemical device with an ampoule inserted and another ampoule lying next to the device.

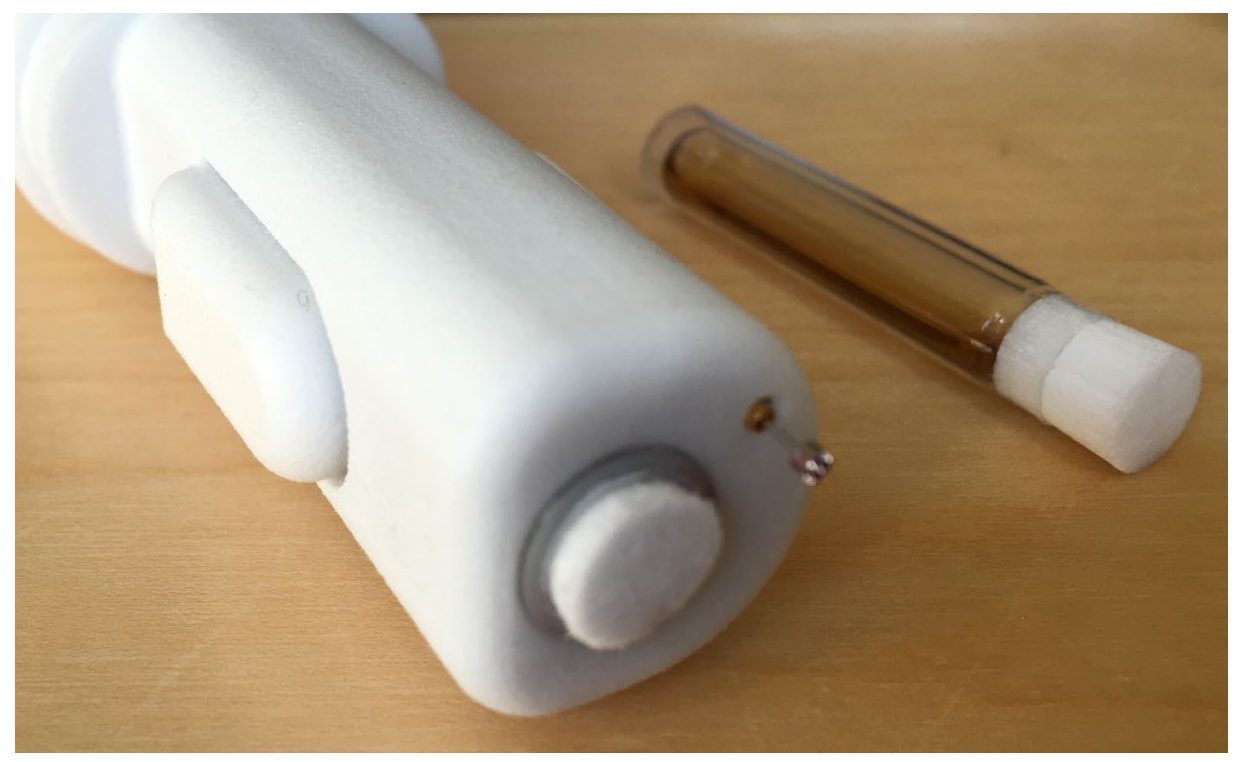

Figure 2. The miniaturized electrochemical device including batteries for voltage supply, electrical contacts and ampoule with colorimetric solution inside a glass cylinder and cotton swab for colour detection. 


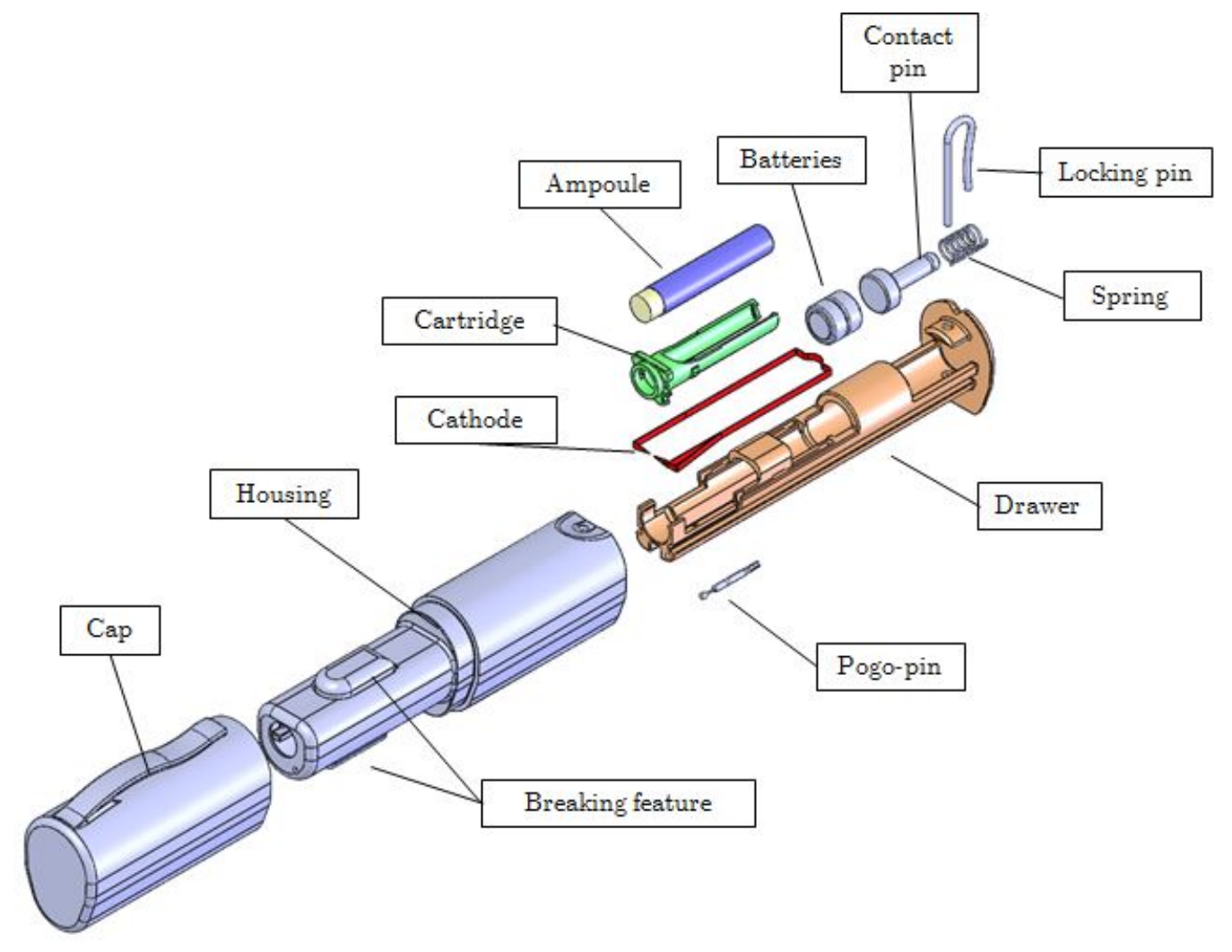


Figure 3. Colour change of the ampoule tip as a function of voltage applied after testing nickel-plated stainless steel for $120 \mathrm{sec}$.

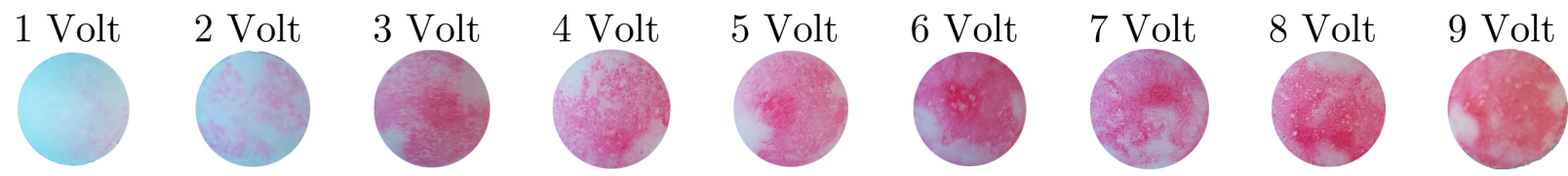


Figure 4. Colour change of the ampoule tip as a function of time after testing at nickel plated stainless steel at $3 \mathrm{~V}$.

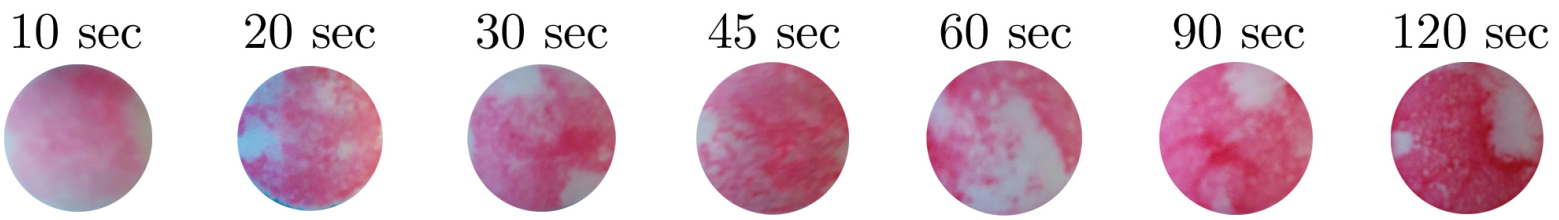


Figure 5. Current responses for various items shown as a function of time with $3 \mathrm{~V}$ applied and resulting colour formation photographed after 120 seconds.
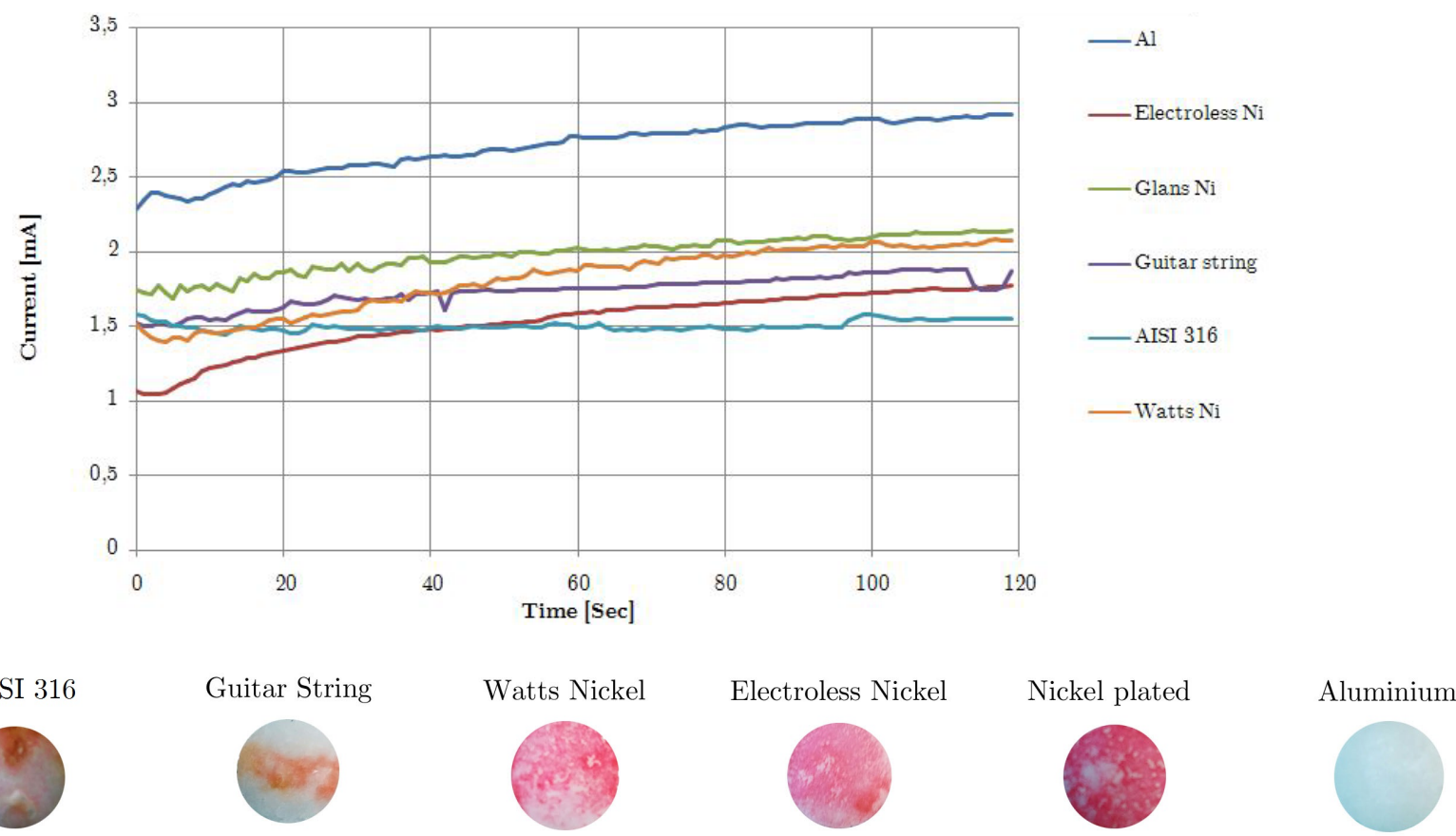
Figure 6. Cotton swab of the ampoule tip on electrochemical device after testing cobalt at $3 \mathrm{~V}$ for $20 \mathrm{sec}$. The metal samples tested were. A: $6.0 \mathrm{wt} . \% \mathrm{Co}, \mathrm{B}: 6.0 \mathrm{wt} . \% \mathrm{Co}$, TiCN $+\mathrm{Al}_{2} \mathrm{O}_{3}, \mathrm{C}: 6.0 \mathrm{wt} . \% \mathrm{Co} \mathrm{TiN}, \mathrm{D:}: 7.5 \mathrm{wt} . \%$ Co, E: 7.5 wt.\% Co, TiCN+ $\mathrm{Al}_{2} \mathrm{O}_{3}+\mathrm{TiN}, \mathrm{F}: 15.0 \mathrm{wt} . \% \mathrm{Co}$, G:15.0 wt.\% Co TiCN+Al2O3+ TiN , H: 0 wt.\% Co (aluminium control disc), I: 64.6 wt.\% Co Dental alloy, K: 33.0 wt.\% Co Dental alloy.

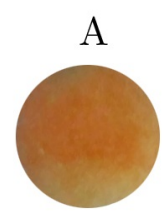

$\mathrm{F}$

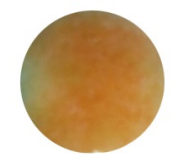

$\mathrm{B}$

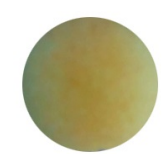

G

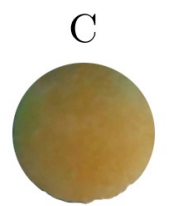

$\mathrm{H}$

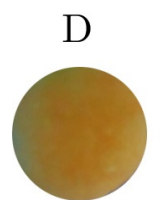

I
$\mathrm{E}$

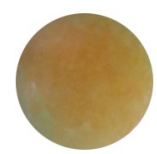

K
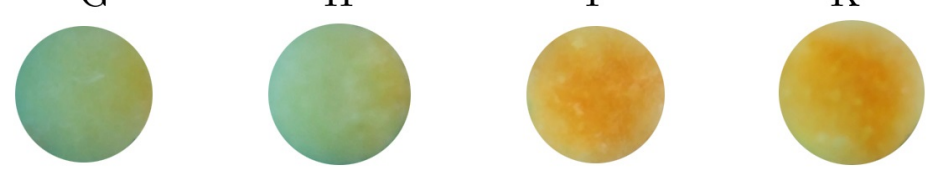
Figure 7. XRF analysis and positive tests of a conventional dimethylglyoxime based nickel spot test and the new electrochemical device test against 163 pieces of jewellery with known nickel content. The column named "total" indicates the number of items tested within the given nickel concentration limits based on previous XRF testing.

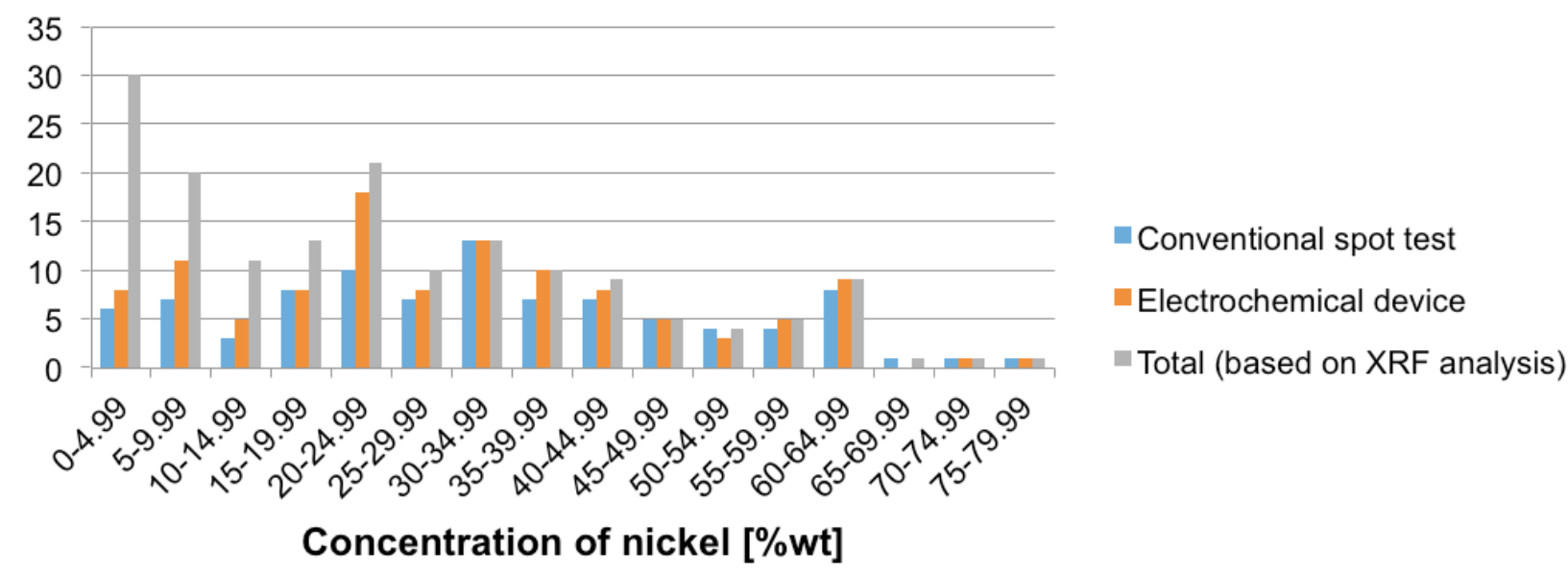


Figure 8. XRF analysis and positive outcomes of a conventional cobalt spot test and the new electrochemical device test against 26 pieces of jewellery with known cobalt content. The column named "total" indicates the number of items tested within the given cobalt concentration limits based on previous XRF testing.

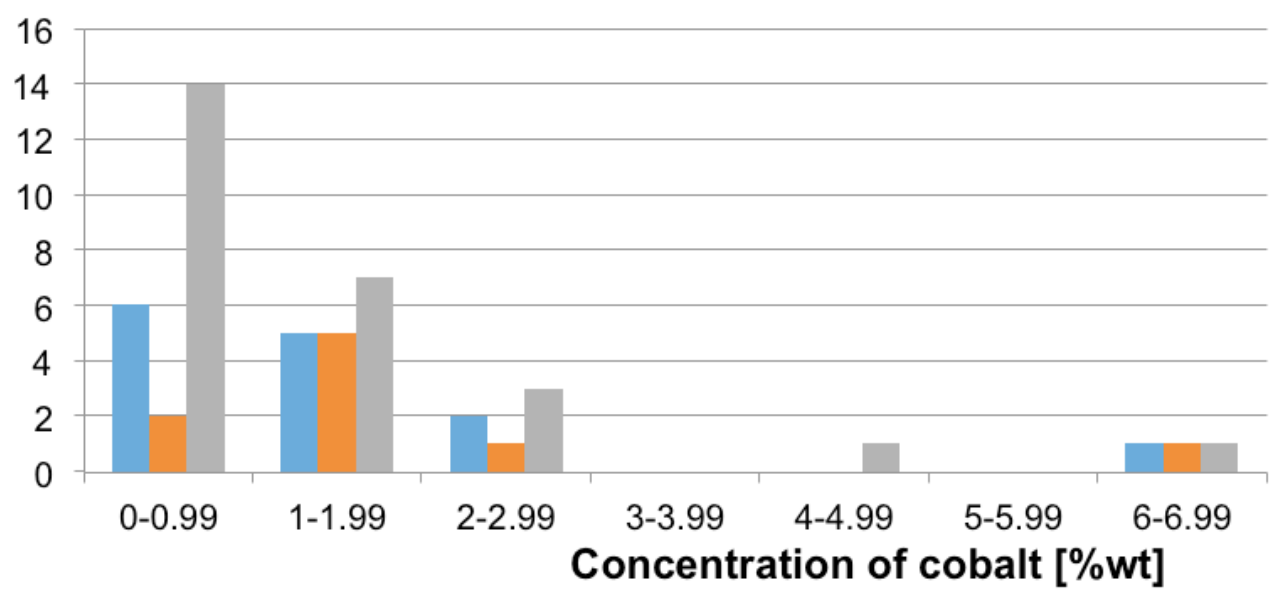

Conventional spot test

Electrochemical device Total (based on XRF analysis) 
Figure 9. Comparison of an electrochemical device cotton part resulting in a positive nickel test reaction (top left) and a conventional dimethylglyoxime negative test reaction (top right) when testing the same earring stick. Electrochemical device testing for cobalt showed a slight positive test reaction, which is however difficult to see with naked eye (bottom left,) whereas conventional cobalt spot testing clearly indicated a positive test reaction (bottom right).
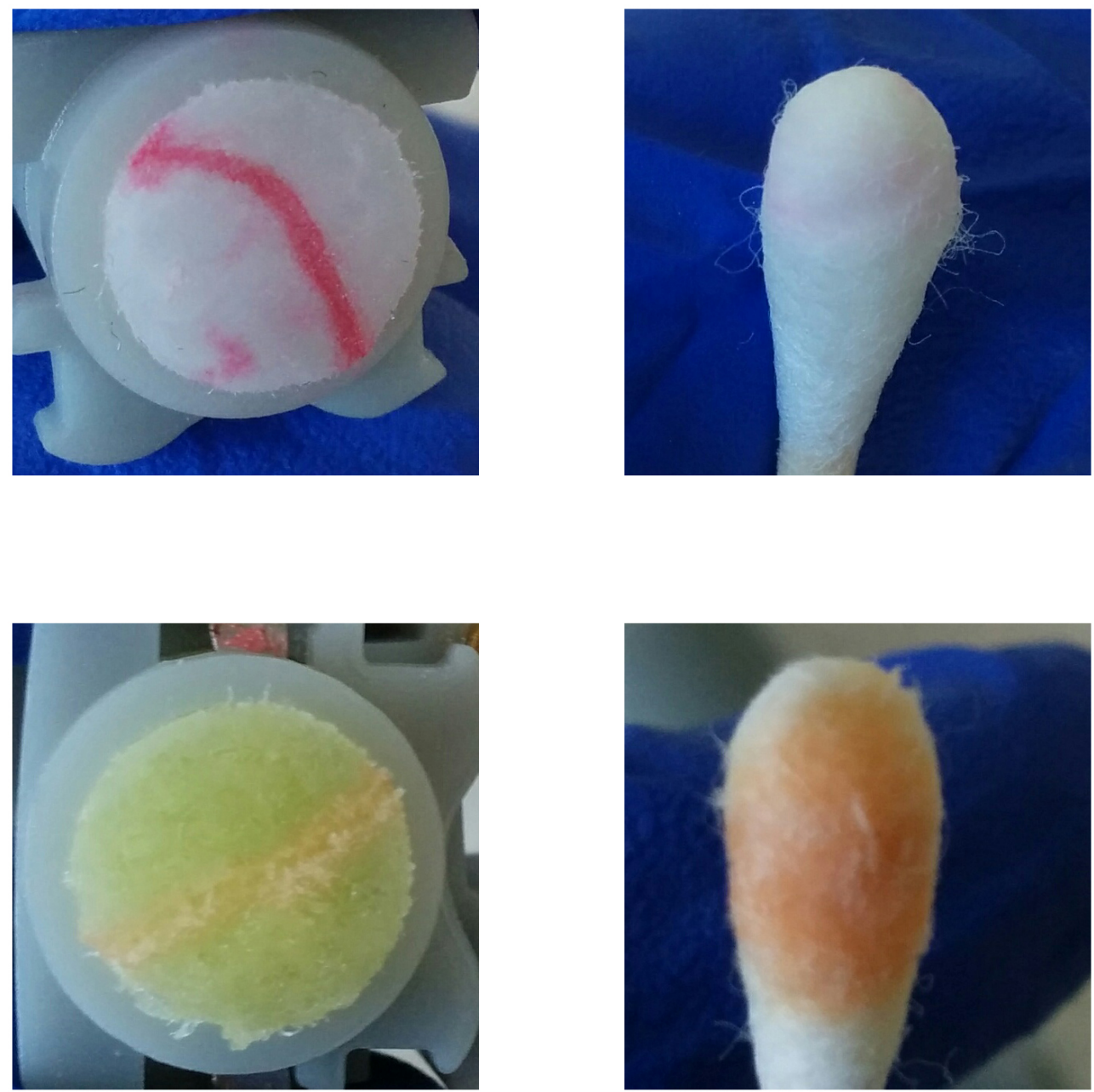


\section{REFERENCES}

1 Uter W, Larese Filon F, Rui F et al. ESSCA results with nickel, cobalt and chromium, 2009-2012. Contact Dermatitis 2016: 75(2):117-21. doi: 10.1111/cod.12582.

2 Zug KA, McGinley-Smith D, Warshaw EM et al. Contact allergy in children referred for patch testing: North American Contact Dermatitis Group data, 2001-2004. Arch Dermatol. 2008: 144(10):1329-36. doi: 10.1001/archderm.144.10.1329.

3 Thyssen JP, Menné T, Johansen JD et al. A spot test for detection of cobalt release - early experience and findings. Contact Dermatitis 2010: 63(2):63-9. doi: 10.1111/j.1600-0536.2010.01749.x. Epub 2010 Jun 18.

4 Thyssen JP, Skare L, Lundgren L et al. Sensitivity and specificity of the nickel spot (dimethylglyoxime) test. Contact Dermatitis 2010: 62(5):279-88. doi: 10.1111/j.1600-0536.2010.01709.x.

5 Bregnbak D, Johansen JD, Jellesen MS et al. Chromium(VI) release from leather and metals can be detected with a diphenylcarbazide spot test. Contact Dermatitis 2015: 73(5):281-8. doi: 10.1111/cod.12406. Epub 2015 Apr 27.

6 Julander A, Hindsen M, Skare L, and Liden C. Cobalt containing alloys and their ability to release cobalt and cause dermatitis. Contact Dermatitis 2009: 60 (3):165-170.

7 Bregnbak D, Zachariae C, Thyssen JP. Occupational exposure to metallic cobalt in a baker. Contact Dermatitis 2015;72(2):118-9. doi: 10.1111/cod.12321. Epub 2014 Nov 24.

8 Thyssen, JP; Jellesen, MS; Menné, T et al. Cobalt release from inexpensive jewellery : has the use of cobalt replaced nickel following regulatory intervention? Contact Dermatitis 2010: 63: 70-76. 
9 Hamann D, Thyssen JP, Hamann CR et al. Jewellery: alloy composition and release of nickel, cobalt and lead assessed with the EU synthetic sweat method. Contact Dermatitis 2015: 73(4):231-8. doi: 10.1111/cod.12434. 